\title{
Offshore Wind farm HVDC Transmission System Protection against $A C$ and DC Faults
}

\author{
Mohamed A. H. El-Sayed ${ }^{1}$, Mohamed M. A. Mahfouz ${ }^{2}$ \\ ${ }^{1}$ Electrical Engineering Dept., Kuwait University, Kuwait, On Leave from Electric Power Dept., Cairo University \\ ${ }^{2}$ Electrical Power and Machines Dept., Helwan University, Cairo, Egypt \\ elsmah@hotmail.com \& mohamed.mahfouz@yahoo.co.uk
}

\begin{abstract}
This paper develops a new one-side, noncommunication protection algorithm for HVDC transmission integrating an offshore variable speed wind farm to a public grid. The proposed digital relay is installed at the AC side bus connecting the farm with the HVDC transmission system. The algorithm protects the HVDC system against DC faults along DC cables and $A C$ faults on the $A C$ sides before the rectifier and after the inverter stations. This algorithm is based on continuous tracking of autocorrelation coefficient between the sampled current pattern and the pre-cycle stored pattern along similar windows. The variation in coefficient magnitude indicates the fault incidence while its sign determines the fault direction. Estimation of autocorrelation from one side for the same measured signal by the relay will eliminate the effects of fault resistance, harmonics and DC components associated with the fault current. To validate the developed algorithm, the HVDC transmission system fed by offshore farm is applied on real wind farm using the manufacture data.
\end{abstract}

Key words. HVDC protection, Auto correlation, relay setting, VSC.

\section{Introduction}

Generally, the generated power from an offshore wind farm is transmitted to public grid by submarine cables. High capacitive currents and high dielectric losses are the main disadvantages of AC submarine cables. Therefore, HVDC transmissions are more feasible than the traditional HVAC for offshore wind energy transmission cables of more than $100 \mathrm{~km}$ length [1-3].

Modern VSC-HVDC technology which is based on IGBT's allows current reversal maintaining the voltage polarity. Moreover, VSCs can independently control the active and reactive power. This relatively modern technology has been developed as the result of important advances in high-power electronics devices [4-6].

Among the existing protection techniques is the simplest Overcurrent using AC measurements from a single bus. But overcurrent protection is difficult to be implemented in HVDC due to possible small wind generation. Moreover, fault direction cannot be provided by overcurrent protection. Therefore, overcurrent is usually used as a backup protection if the main protection fails to trip out the fault in the corresponding zone [7-10]. The main issue associated with the smart grid is to implement communication-based protection techniques. However, these techniques require backup protection scheme to manage communication link failures [7]. The differential protection techniques are based on measured AC signals from both ends of the lines. This technique is highly selective in detecting the fault types and provide inherent directionality. However, in fault cases with long transmission lines, the differential protection results in a significant time delay of far line end communication. Moreover, the differential protection will clearly fail in case of communication link interruption. In addition, moisture fog in offshore regions adds attenuation to the communication signals, which may affect the accuracy of two end protection accuracy in HVDC transmission.

In traveling-wave-based protection, the initial voltage surge propagates from the fault point to the relay end. Thereby, the travelling wave protection relies on the detection of a steep initial wave front. Traveling-wavebased protection can be used as the main protection for HVDC transmission lines [5, 8]. However, this protection technique is sensitive to fault transition impedance. Although traveling wave can operate using information received from one end relay, it becomes unreliable for high impedance faults $[9,10]$.

The main purpose of this paper is to develop a new non-communication protection algorithm; uses the $\mathrm{AC}$ circuit breaker to clear the $\mathrm{DC}$ and $\mathrm{AC}$ faults for the HVDC transition system. This algorithm relies on the measured current signals for detecting the faults and defining their direction. The protection algorithm utilizes the available current transformer of the relay without any extra equipment. During a fault, the current pattern is different from the normal current pattern. This difference is mathematically expressed by autocorrelation coefficient between two successive current patterns shifted by one cycle. If the magnitude of the coefficient exceeds the threshold, the fault is detected. The proposed protection scheme has the following inherent advantages:

- The proposed algorithm is one-ended protection scheme and no extra communication links are needed. Therefore, it does not suffer from communication interruption in other protection schemes. 
- The difficulties of determining the wave arrival time is avoided in case of fault inception at zero or small voltage angles and faults close to the protective relay.

- The protection scheme will differentiate between internal and external faults based on the sign of crossalienation coefficients irrespective of voltage and current magnitudes. Once an internal fault is detected, a trip signal will be generated to open the AC circuit breaker.

Simulation results are executed by using Simulink /MATLAB are carried out to validate the proposed algorithm for fault detection and direction.

\section{Studied Wind Farm HVDC Power System}

The single-line diagram of the studied power system is displayed in Figure (1). The system consists of an offshore wind farm having Permanent magnet synchronous generators (PMSGs) [11-14]. The studied wind farm with total capacity 115.2 MW consists of three subsystems with medium voltage $22 \mathrm{kV}$ feeders and each subsystem contains of Thirty two $1200 \mathrm{~kW}$ variable speed wind turbines These wind turbines are distributed into four rows where the wind speed for each row is recorded. Each turbine has a step up transformer with voltage ratio of $690 \mathrm{~V} / 22 \mathrm{kV}$. The offshore wind farm is integrated to onshore public grid by submarine DC cable of length $150 \mathrm{~km}$. The typical VSC-HVDC transmission system consists of two HVDC cables, converter stations, DC capacitors, AC filters and inverter station. Three-level NPC converters with a switching frequency of $2 \mathrm{kHz}$ and a $7000 \mu \mathrm{F}$ capacitor is used in the DC link The active power of VSC is controlled by adjusting the voltage angle, where the reactive power flow depends on the AC system voltage compared to the converter voltage $[15,16]$.

\section{Methodology of the Proposed Protection Scheme:}

When a fault occurs on HVDC line, high over current is generated due to rapid discharging of DC-link capacitor. In addition the high AC side current contribution into the fault flows through the freewheeling diodes and my damage the converter devices. Therefore, the HVDC transmission stem protection requires fast and systematic algorithm to efficiently defining the threshold of relay setting under different system disturbances. Consequently, the proposed protection algorithm is based on the efficient autocorrelation estimation of movable windows for two successive cycles with high sampling rate of the measured current patterns of 2700 samples/window for systems with $50 \mathrm{~Hz}$ frequency, which is much higher than the sampling rate of conventional AC protection schemes with 80-100 samples/window. It should be noted that; faults on HVDC submarine cables are permanent and not self-healing like AC overhead transmission line. On the other side, the HVDC CBs are more complex than AC CBs and need appropriate scheme to interrupt the non-zero crossing fault currents. In order to reduce the $\mathrm{CB}$ cost and to avoid high rated wear of $\mathrm{DC} C \mathrm{CBs}$, the available $\mathrm{AC} C \mathrm{CB}$ s is utilized in the proposed HVDC protection against different faults on DC cables or AC terminals of HVDC system. Therefore, the proposed digital protective relay $(\mathrm{R})$ is located at the $\mathrm{AC}$ side before the rectifier station of the offshore wind farm, as indicated in Fig. (1).

\subsection{Autocorrelation between current patterns}

The main feature of the autocorrelation of the successive current pattern is independent of the shape and the magnitude of the current waveform as it evaluates only the deviation between the stored successive current patterns [17]. Moreover, this feature is very important for reliable relay operation by eliminating the effects of load changes, fault resistance and the DC components. The autocorrelation coefficient is generally evaluated between two different sampled variables ( $\mathrm{r}$ and $\mathrm{s}$ ) with sampling rate Ns per cycle [18-19] as follows:

$\sigma=\frac{\sum_{n=1}^{N s} r_{n} s_{n+N s}}{\sqrt{\sum_{n=1}^{N s} r_{n}^{2} \sum_{n=1}^{N S} s_{n+N s}^{2}}}$

For a movable window with K-Width, the autocorrelation pattern between successive windows shifted by one cycle is given by;

$\sigma=\frac{\sum_{n=1}^{k}\left(r_{n}-\bar{r}\right)\left(s_{n+N s}-\bar{s}\right)}{\sqrt{\sum_{n=1}^{k}\left(r_{n}-\bar{r}\right)^{2} \sum_{n=1}^{K}\left(s_{n+N s}-\bar{s}\right)^{2}}}$

Where; $\bar{r}$ and $\bar{s}$ are the arithmetical mean for the reference and tested window patterns.

The proposed algorithm is applied to the measured sampled current patterns for two successive windows with $\mathrm{K}^{\text {th }}$ samples width with total Ns samples per cycle. The autocorrelation between the correlated current windows is:

$\sigma=\frac{\sum_{n=1}^{k}\left(i_{n}-\bar{r}\right)\left(i_{n+N s}-\bar{s}\right)}{\sqrt{\sum_{n=1}^{k}\left(i_{n}-\bar{r}\right)^{2} \sum_{n=1}^{K}\left(i_{n+N s}-\bar{s}\right)^{2}}}$

The values of $\bar{r}$ and $\bar{s}$ for the correlated windows pattern are;

$\bar{r}=\frac{1}{k} \sum_{n=1}^{k} i_{n}, \quad \bar{s}=\frac{1}{k} \sum_{n=1}^{k} i_{n+N s}$

\subsection{Proposed Fault Detection Algorithm}

The proposed protection algorithm schematic diagram for a single pole in the bipolar HVDC system is shown in Fig. (2), the protective relay $(\mathrm{R})$ is responsible to create the trip signal to open the associated AC circuit breaker (CB).

After fault inception, the follow-up calculation of the autocorrelation coefficient is applied on the current patterns. The pre-fault $\sigma$ magnitude and sign between two windows of current patterns are equal +1 as the two patterns are symmetrical in magnitude and have same sign. The coefficients magnitudes and signs during the fault conditions start to change depending on fault direction.

The coefficient may be positive or negative for forwarding (positive direction) or negative for backwards faults (negative direction), respectively. For healthy feeder, the coefficient is positive and close to unity. A prespecified set value less than unity $(\sigma$ th) should be defined 
to avoid any false detection due to the dynamic nature of current signals according to the changing wind speed, fault resistance and discretization error of the current waveforms. This setting requires extensive numerical simulations where all possible operation scenarios and fault conditions are covered. As a result, the value of $\sigma^{\text {th }}$ is defined by 0.9 . All faults in the region of HVDC transmission system are isolated by tripping all AC breakers operated by the forward relays. Then, the faulty component will be finally isolated by switching off DC isolating switches (DCISW) at HVDC terminals.

The concept of the proposed protection algorithm is summarized in the flowing steps:

- Sampling the current measured by the protective relay at $\mathrm{R}$.

- $\quad$ Estimating autocorrelation $(\sigma)$ between each two similar movable current windows for two successive cycles.

- Checking the sign of the estimated $\sigma$. If it is positive, the fault considered as forward; otherwise, for negative $\sigma$, it is backward.

- If $\sigma$ is negative with value between $(0.0 \geq \sigma>-0.9)$; that means the fault is backward. For such cases, the fault is external and the relay action is blocking.

- If $\sigma$ is positive $\sigma$ and less than 0.9 the fault can be considered as forward at three cases are the following three locations:

$>$ The fault is forward along the DC cables. In such case, the relay action is tripping instantaneously to open the AC circuit breaker.

$>$ The fault is forward and located before the converter station which related to the AC side of offshore wind farm. For such cases, the relay action is tripping instantaneously to open the AC circuit breaker.

$>$ The fault is forward and located after inverter station which related to the public AC grid side and the relay action is tripping. For such cases, the relay action is tripping and can be used as grid-side backup protection.

The effects of harmonics, DC component in fault current and fault resistance on the accuracy of protection scheme are effectively reduced by continuous tracking of the autocorrelation coefficients between the sampled windows of same current signal and same cable end. Current signal measurements are sufficient without extra voltage signals to implement this simple and cost-effective algorithm.

\section{Results and Discussions:}

\subsection{Normal operation}

For the studied offshore wind farm with HVDC transmission system, the instantaneous wind speed is displayed in Fig. (3.a). This speeds is changing between 10.7 $\mathrm{m} / \mathrm{s}$ and $9.67 \mathrm{~m} / \mathrm{s}$ during the simulation period of $1.5 \mathrm{~s}$. The HVDC voltage and the transmitted DC power are shown in Figure (3.b). The results indicate that the system under normal operation condition has a constant stable DC voltage with the value of 1pu. In addition, the DC power is stable and constant with an amount of $0.4 \mathrm{pu}$.
Similarly, the main bus voltages and currents signals at PCC, rectifier bus and inverter bus station are illustrated in figures (3.c and 3.d) respectively. The buses' three phase voltages and currents waveforms are symmetrical.

In order to check the performance of the rectifier controller in the offshore farm side, the $\mathrm{d}$ and $\mathrm{q}$ components of the offshore currents are plotted in Figure (4.a). From these curves, it can be noticed that the current components are tracking well their reference values.

The $\mathrm{d}$ and q-components are settling fast after short transient periods. The settled vales of Id and Iq are 0.9 and $0.25 \mathrm{pu}$, respectively, while the modulation index reaches a value of 0.8 . The simulated signals of the inverter controller is nearly identical to the previous rectifier one as presented in Figure (4.b). The d and q-components are also settling fast after short transient periods with a modulation index of 0.7 . At the onshore VSC terminal, the DC voltage is kept constant at its reference value independent on the changes in the active power.

The model is therefore validated and it provides a good performance of offshore wind farm under actual operation conditions.

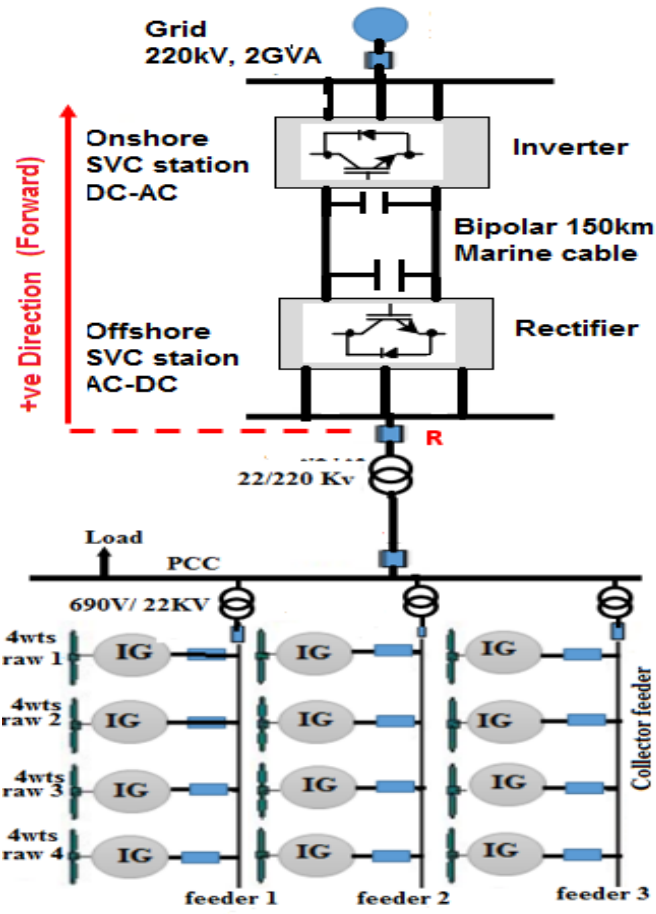

Fig.1: Studied wind farm- HVDC system

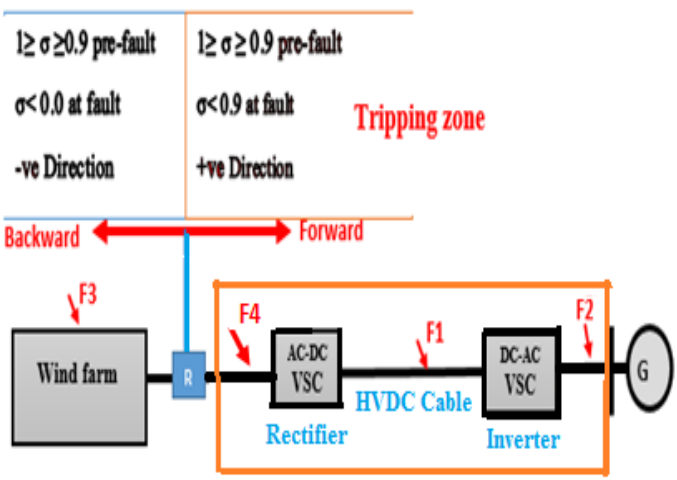

HVDC Transm, System

Fig. (2) Proposed HVDC system protection algorithm 


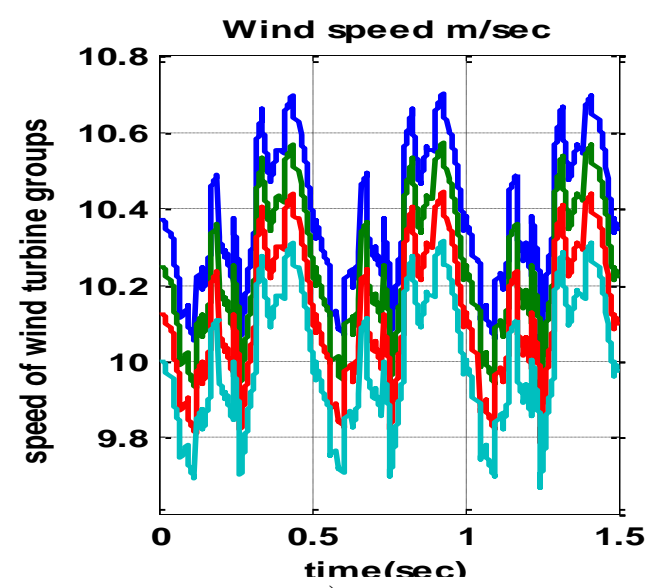

a)

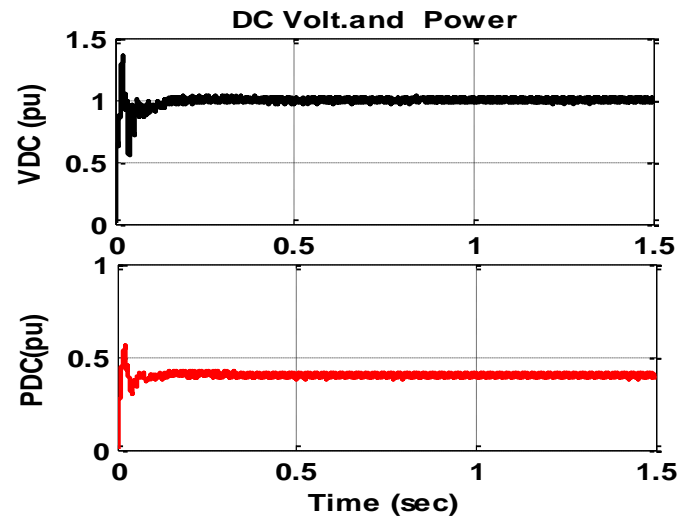

b)

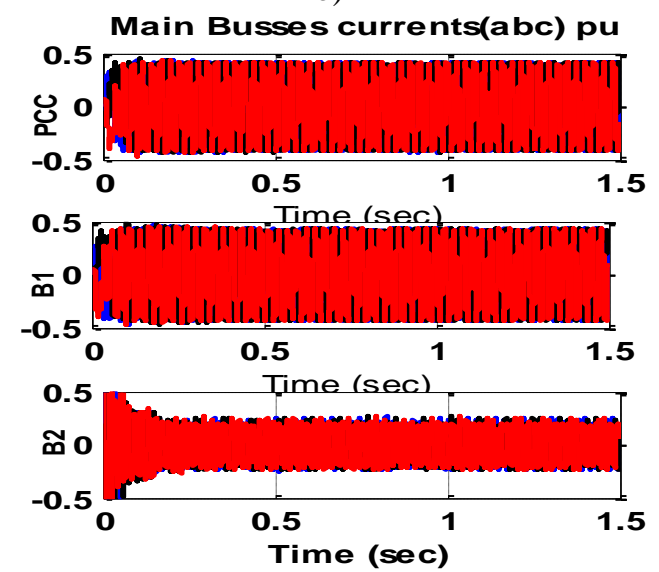

c)
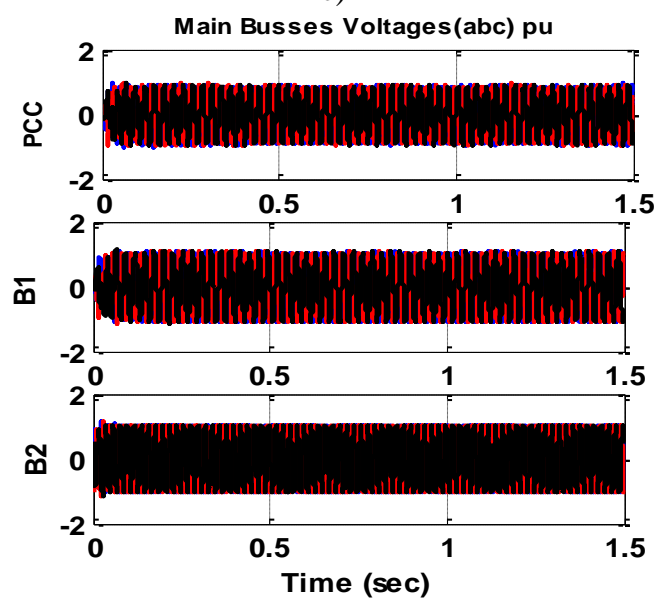

d)

Fig. 3: Steady state; a) wind speed, b) HVDC, c) Buses volt. \& d) Buses currents
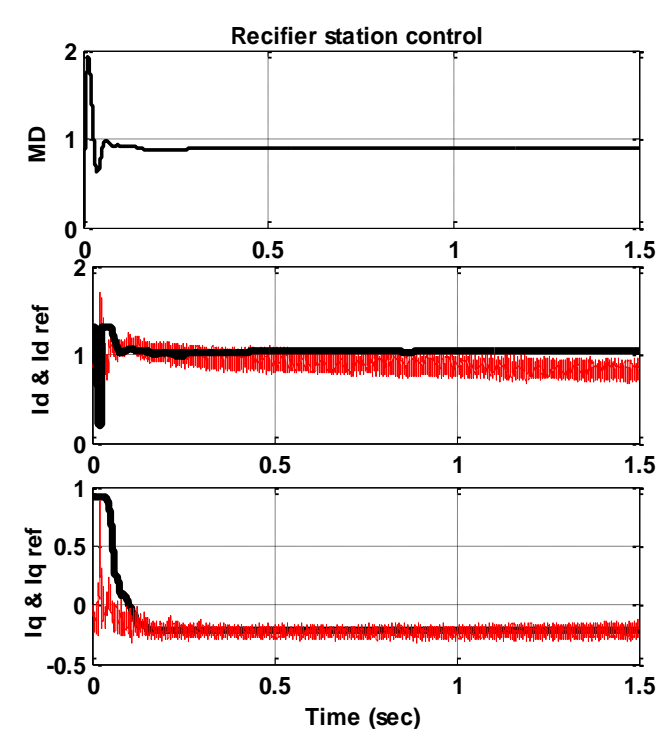

a)
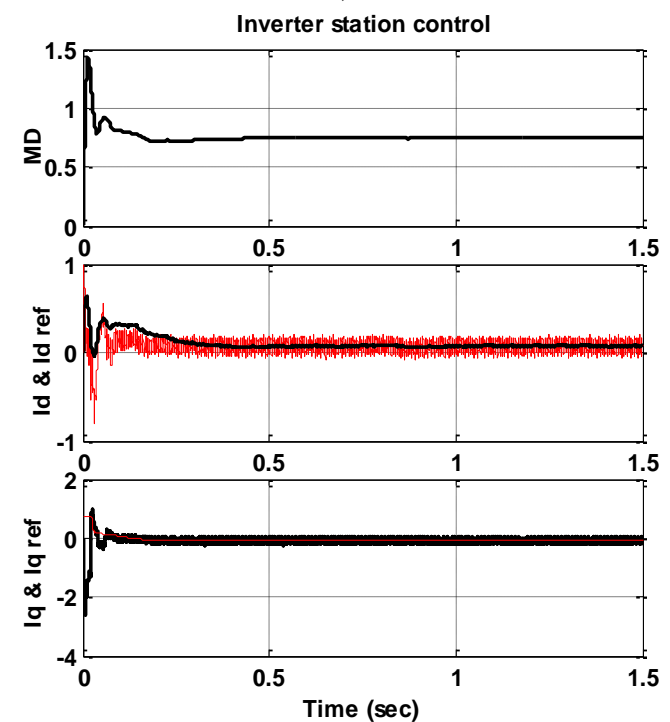

b)

Fig.4: VSC controllers a) rectefier and b) Inverter station

\subsection{Fault conditions}

The simulation results of the following study cases are being considered and analyzed:

$>$ DC faults:

- Two-pole earth fault at F1 in the HVDC cable.

- One-pole earth fault at F1 in the HVDC cable

$>$ AC faults

- At F2 after the inverter bus of HVDC system.

- At F4 before the converter bus of HVDC system.

- At F3 inside the wind farm zone.

$>$ Effect of fault resistance and fault location

\subsubsection{Two-Pole-Earth DC fault}

In this study case, a simulation of two-pole to earth fault at different locations on the HVDC transmission cable are carried out. The main task here is to determine the autocorrelation $(\sigma)$ range for this type of fault. At a fault location F1 which shown in Figure (2). Figure (5) presents calculated autocorrelation $(\sigma)$. Before the fault incident, the autocorrelation coefficient is very close to unity greater than the threshold $\sigma_{\text {th. }}$. While during the fault occurrence, the value of $\sigma$ changed from unity to a 
positive value of 0.2 less than 0.9 , which indicates an internal forward fault case; accordingly, the relay $\mathrm{R}$ action is tripping instantaneously to open the circuit breaker.

\subsubsection{One-Pole-Earth DC Fault}

At a fault location F1 which shown in Fig.2. Figure (6) illustrates the calculated $(\sigma)$ during this case of fault. Before the fault incident, $\sigma$ is very close to unity greater than $\sigma_{\text {th }}$. While during the fault, $\sigma$ changed from unity to +0.16 , which is less than the value of $\sigma$ th indicating a forward and internal fault case; accordingly, the relay $\mathrm{R}$ action is tripping to open of the circuit breaker instantaneously.

\subsubsection{AC Three-phase Fault after Inverter}

Three-phase to earth fault after the inverter station inside the public grid zone is selected at F2. Figure (7) illustrates the estimated $(\sigma)$ during this case of fault. Before the fault incident, $\sigma$ is very close to unity greater than $\sigma_{\text {th. }}$. While during fault, the value of $\sigma$ still positive which indicates a forward fault, while the autocorrelation coefficient $(\sigma)$ is changed to +0.35 . This autocorrelation coefficient is greater than the two DC cable fault cases, which indicates a forward but fault. Accordingly, the relays action is tripping as backup protection for the grid zone and tripping after a delay time.

\subsubsection{AC Three-Phase Fault in the wind farm}

The estimated autocorrelations $(\sigma)$ are depicted in Figure (8). Before the fault incident, the value of $\sigma$ is very close to unity and greater than the assigned threshold. While during the fault, the value of $\sigma$ changed from unity to a negative value of (-0.7), which indicates a backward external fault case. The backward fault range is set as; (-0.9 $\leq \sigma<0$ ), accordingly, the relay $\mathrm{R}$ action is blocking.

\subsubsection{Effect of fault resistance and location}

In order to define the effect of fault resistance on the setting value of the protective relay, the fault simulation is carried out with the different fault resistance applied in 10 $\Omega$ intervals up to $60 \Omega$. The results of varying the fault resistance indicated that the maximum change in $\sigma$ at 60 ohm fault resistance is less than $5 \%$. Similarly, the effect of fault location on the setting value of the protective relay is carried out in $25 \mathrm{~km}$ intervals of the HVDC line. The results indicated that the difference of $\sigma$ for line faults near converter and inverter station is less than $8 \%$ as indicated in Table 1.

Table 1: Effect of fault resistance and fault location on the autocorrelation coefficients

\begin{tabular}{cccc}
\hline \multicolumn{2}{c}{ Effect of fault resistance } & \multicolumn{2}{c}{ Effect of fault location } \\
\hline $\mathbf{R}_{\mathbf{f}}(\boldsymbol{\Omega})$ & $\mathbf{( \sigma )}$ & $\mathbf{L}(\mathbf{k m})$ & $(\boldsymbol{\sigma})$ \\
0 & 0.200 & 0 & 0.195 \\
10 & 0.203 & 25 & 0.197 \\
20 & 0.205 & 50 & 0.199 \\
30 & 0.207 & 75 & 0.200 \\
40 & 0.209 & 100 & 0.210 \\
50 & 0.210 & 125 & 0.214 \\
60 & 0.211 & 150 & 0.216 \\
\hline
\end{tabular}

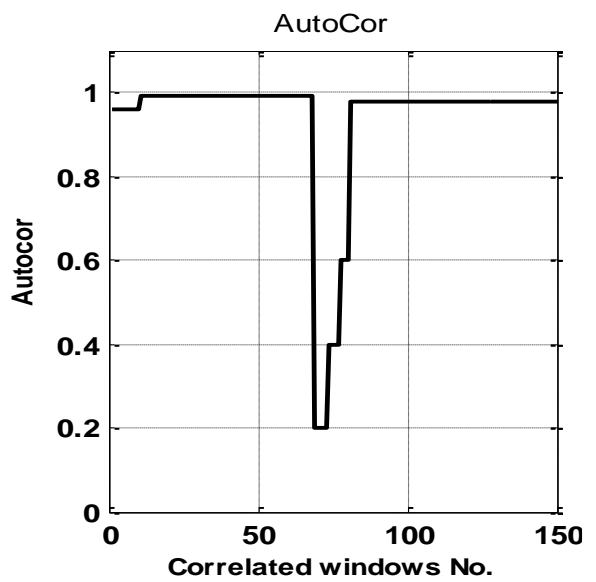

Fig. 5: Auto-cor. at R for HVDC 2-pole fault AutoCor

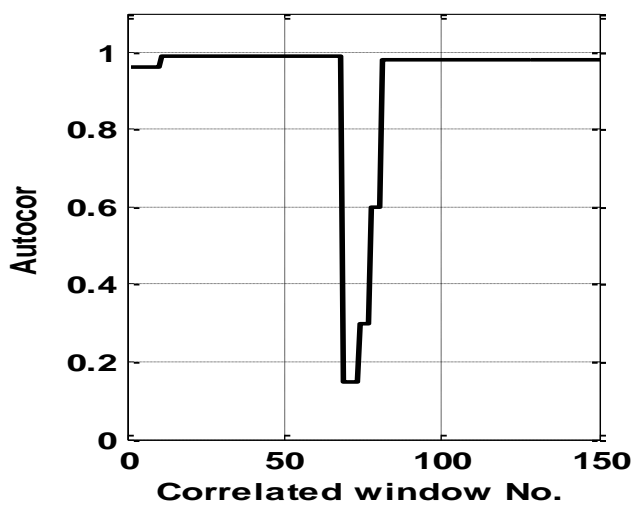

Fig.6: Auto-cor. at R for HVDC one-pole- fault

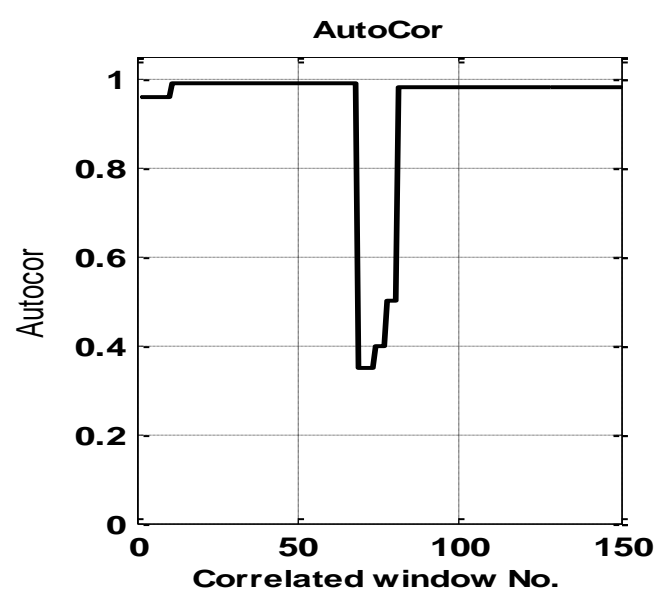

Fig.7: Auto-cor. at $\mathrm{R}$ for grid side fault

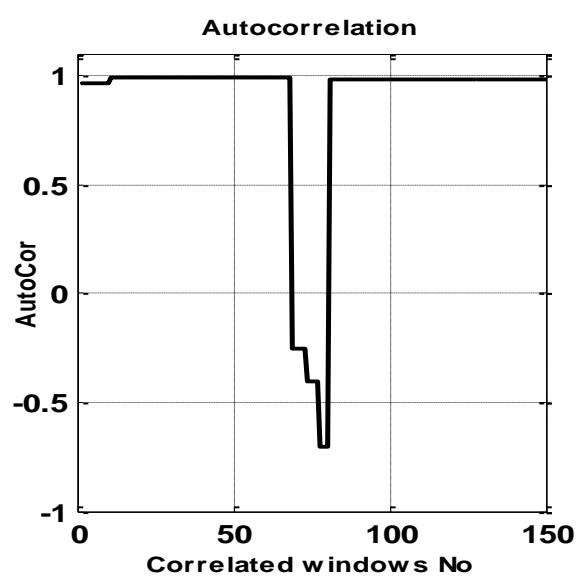

Fig. 8: Auto-cor. at R location for Wind fault 


\subsection{Proposed Relay Actions}

Table 2 summarizes the fault simulation results for the studied system and the relay action of the proposed protection scheme. The results indicate that the values of autocorrelation $(\sigma)$ for forward faults are positive and negative for external faults.

Table 2: Different HVDC system faults and the corresponding relay action

\begin{tabular}{llcc}
\hline \multicolumn{1}{c}{ Faults } & \multicolumn{1}{c}{ location } & $\boldsymbol{\sigma}$ & Relay action \\
\hline DC one pole & F1,Cable & 0.16 & Tripping \\
DC two- pole & F1 ,Cable & 0.2 & Tripping \\
AC-3 -phase & F2,Inverter & 0.35 & Tripping \\
AC-3 -phase & F4,Rectifier & 0.14 & Tripping \\
AC-3 -phase & F3, Wind & -0.7 & Blocking \\
\hline
\end{tabular}

\section{Conclusions}

A new directional one-end protection technique against DC and AC side faults was developed for HVDC transmission system fed by offshore wind farm. This technique based on continuous tracing of the current patterns autocorrelation for two successive current patterns measured at the AC bus. The proposed scheme is cost effective as it can implemented without any need of any extra signal measurements or communications between the HVDC line ends. The Non-communication scheme enhances the relay response by avoiding communication delay and signal attenuation in foggy offshore regions of the two end protection schemes. As the proposed algorithm depends on autocorrelation of continuous current windows of the same current signal at same end side, it is able to perform efficiently the fault detection under different loading levels, fault resistances, harmonics and fault inception angle. These are the main advantages and the added values for the proposed one-end autocorrelation protection algorithm. The fault direction as forward or backward had been verified based on the autocorrelation sign, while the fault detections are based on the magnitude of the autocorrelation coefficients. The obtained results indicate that the proposed protection scheme for HVDC system is reliable and can be implemented for digital protection of similar real offshore wind-HVDC system without extra measurements or communication links.

\section{References}

[1] S. Le Blond, R. Bertho, D. Coury, J. Vieira, "Design of protection schemes for multi-terminal HVDC systems" , Renewable and Sustainable Energy Reviews, vol. 56, pp. 965-974, Elsevier 2016

[2] P. Wang, X-P Zhang, P. Coventry, R. Zhang, Z. Li, "Control and protection sequence for recovery and reconfiguration of an offshore integrated MMC multi-terminal HVDC system under DC faults", Electric Power and Energy Systems, vol. 86, pp. 81-92, Elsevier 2017.

[3] J. Zhang, J. Suonan, Z. Jiao, and G. Song, "A fast full line tripping distance protection method for HVDC transmission line," in Proc. Power Syst. Technol. Int. Conf., pp. 1-7, 2012.
[4] C. Dierckxsens, K. Srivastava, M. RezaS. Cole, J. Beerten, R. Belmans, "A distributed DC voltage control method for VSC MTDC systems", Electric Power System Research, vol. 82, pp. 54-58 Elsevier, 2012.

[5] G. Buigues, V. Valverde, D.M. Larruskain and etal. "DC protection in modern HVDC networks: VSC-HVDC and MTDC systems" International Conference on Renewable Energies and Power Quality (ICREPQ'16), Madrid (Spain), pp.300-305, 2016. [6]Yuan-Kang Wu, Li Wang, Yong-Qing Huang, Shu-Wei Liu," Overview of Important State-of-the-Art Technologies in Offshore Wind Energy Systems", International Journal of Smart Grid and Clean Energy, vol. 2, No. 2, May 2013.

[7] Chunyi Guo, Chengyong Zhao, Maolan Peng, Wei Liu, " Investigation of a Hybrid HVDC System with DC Fault RideThrough and Commutation Failure Mitigation Capability", Journal of Power Electronics, Vol.15, No.5, pp.1367-1379, 2015. [8] H. Livani, C. Evrenosoglu, " A single-ended fault location method for segmented HVDC transmission line", Electric Power System Research, vol. 107, pp. 190-198, Elsevier 2014.

[9] X. Zheng, N. Tai, J.Thorp, G.Yang, "A transient harmonic current protection scheme for HVDC transmission line," IEEE Trans. Power Del., vol. 27, no. 4, pp. 2278-2285, Oct. 2012.

[10] X. Liu, A. H. Osman, and O. P. Malik, "Hybrid travelling wave/boundary protection for monopolar HVDC line," IEEE Trans. Power Del., vol. 24, no. 2, pp. 569-578, Apr. 2009.

[11] Z. Zhang, A. Chenb, A. Matveevb, R. Nilssena, A. Nysveen, " High-power generators for offshore wind turbines", Elsevier, Energy Procedia, Vol. 3561, pp 52- 61, 2013.

[12] Abdulhamed H., Reza K.,"Wind Turbine Control Using PI Pitch Angle Controller", IFAC Conference on Advances in PID Control, Brescia ,Italy, 2012.

[13]Boukhezzara,B.,Lupua,L.;Siguerdidjanea,H.,and etal,, "Multivariable control strategy for variable speed, variable pitch wind turbines", Renewable Energy,vol.32, pp.1273-1287, 2007.

[14] Feng, Gao., Daping, Xu., and Yuegang, L., "Pitch control for Large-scale Wind Turbine Based on Feed forward Fuzzy PI",WCOICA, 25-27,China, 2008.

[15] A. Li, Z. Cai, Q. Sun, X. Li, D. Ren, and Z. Yang, "Study on the dynamic performance characteristics of HVDC control and protections for the HVDC line fault," in Proc. Power Energy Soc. Gen. Meeting, 2009, pp. 1-5.

[16] M. You, B. Zhang, and R. Cao, "Study of non-unit transientbased protection for HVDC transmission lines," in Proc. AsiaPacific Power Energy Eng. Conf., 2009, pp. 1-5.

[17] S. Tom, J. Thomas, "HVDC Transmission line protection based on transient power", Science Direct, Elsevier Procardia Technology, vol. 25, pp. 660-668, 2016.

[18] M.M. A. Mahfouz, M. M. Eissa, "New High Voltage Directional and Phase Selection Protection Technique Based on Real Power System Data”, IET Gener.Transm. And Disturb. Journal, Vol. 6, Issue 11, pp 1075-1085, Nov.2012.

[19] Mohamed.M.A. Mahfouz, Mohamed A. H. El-Sayed "Smart grid fault detection and classification with multidistributed generation based on current signals approach IET Gener.Transm. And Disturb, Vol.10, Issue 16, pp. 4040 - 4047, Dec. 2016 